\title{
What Has IoT Got to Do with HR and People: A Case of Delloitte
}

\author{
Ila Mehrotra Anand ${ }^{1}$, Saurabh Anand ${ }^{2}$ \\ ${ }^{1}$ Assistant Professor, Institute of Business Management, GLA University, Mathura, India. \\ E-mail: ila.mehrotra@gla.ac.in \\ ${ }^{2}$ Assistant Professor, Department of CEA, Institute of Engineering and Technology, GLA University, Mathura, \\ India. E-mail: saurabh.anand@gla.ac.in
}

Article History: Received: 11 January 2021; Accepted: 27 February 2021; Published online: 5 April 2021

\begin{abstract}
Interacting with software using keyboard and mouse will soon be history. Voice, speeches, gestures are the next big thing in communication. IoT will certainly produce a large amount of people-related data and it is this data that is going to be really useful for decision taking purposes. HR would need to incorporate technology to successfully control the organizational human resources. IoT will allow us to access our data and other applications like Continuous Performance Management, where digital culture is required to create a genuinely valuable connection between an employee and his or her staff. It also helps to exchange thoughts and experiences through social media collaboration which is a driving force for all employees. The paper tries to analyze the role of IoT in People analytics, challenges associated with it and how Delloitte Canada has gone about implementing it across their organization.
\end{abstract}

Keywords: Internet of Things, Decision Making, HR, Technology, Performance.

\section{Introduction}

In the last decade, Body Sensor Networks and The Internet of Things have grown rapidly [1]. The Internet of Things (IoT) has already started to have a profound impact on everything around us. Recently, IoT has gained prominence in academia and industry as it aims at creating interconnections between individuals, objects and the networks so that it is flawless to capture, process, store and visualize the data from the sensors[2]. IoT is a system which connects many devices with each other and further this is connected with people via networks [3]. It is predicted that by the year 2020 there will be 20 billion IoT devices, generating and sharing a massive amount of information. This is making HR executives and CEO's to think how to incorporate IoT into HR.

Employees keep busy with meetings, decision making, emails, meeting standards etc. at the work place, leaving them with no time to analyze the productivity of their own self. The requirement to assess, gauge and spoor one's performance has molded the entire cynosure to mobile computation tools, wearables- which are devices that can be computed based on the data fed to them. With this first hand data from employees' by means of wearable devices, HR departments may generate a vibrant, optimistic and a systematic work environment for evaluating employee fecundity, communication patterns, trends related to people, and how pooling of resources can be done by the teams for superior results[4]. The different places where IoT is being used is illustrated below in figure 1.

\section{Repercussion of Using IoT}

- Physical Attacks - This can involve inserting legitimate confirmation token into a compromised system, booting and/or inserting with fake or altered programs ("re-flashing"), and side channel/ environmental attack, both prior and following in-field exploitation[5]. Such potential then include assured "validation" of the IoT system's software and data integrity like authentication tokens

- Credentials Compromise - 'Includes brute force attacks on tokens and (weak) authentication algorithms, physical intrusion or side channel attacks, and malicious cloning of authentication tokens that reside in the User Contact Identity Module.'[6]

- Attacks related to Configuration - These are like counterfeit changes in the updation of software / design, creator, client or device misconfiguration, misconfiguring or misuse of the access control lists [7]. 


\begin{tabular}{|c|c|}
\hline $\begin{array}{l}\text { HEALTHCARE } \\
\text { - Care Provider } \\
\text { - Medical Device Manufacturer } \\
\text { - Health Insurance }\end{array}$ & $\begin{array}{l}\text { LOGISTICS } \\
\text { - Asset Tracking Services } \\
\text { - Shipping }\end{array}$ \\
\hline $\begin{array}{l}\quad \text { ENERGY/UTILITIES } \\
\text { - Electricity, Water, Waste } \\
\text { - Aggregator } \\
\text { - Meter Manufacturer } \\
\text { - Pipeline/Refinery Management }\end{array}$ & $\begin{array}{l}\quad \text { PUBLIC INFRASTRUCTURE } \\
\text { - Traffic Control } \\
\text { - Facilities Management } \\
\text { - Emergency Services } \\
\text { - Security/Defense }\end{array}$ \\
\hline $\begin{aligned} & \text { BUILDING/ CONSTRUCTION } \\
& \text { - Energy Management } \\
& \text { - Security }\end{aligned}$ & $\begin{array}{l}\quad \text { TRANSPORATION } \\
\text { - AutomotiveInfotainment H'ware/Svcs } \\
\text { - Fleet Management } \\
\text { - Transportation Insurance } \\
\text { - Mass Transporation }\end{array}$ \\
\hline $\begin{array}{l}\quad \text { RETAIL/CONSUMER } \\
\text { - Appliances/Housewares } \\
\text { - Personal Device Manufacturer } \\
\text { - Signage } \\
\text { - Vending }\end{array}$ & $\begin{array}{l}\text { INDUSTRIAL } \\
\text { - Manufacturing/Fabrication } \\
\text { - Laboratory/Pharma } \\
\text { - Agribusiness/Farming }\end{array}$ \\
\hline
\end{tabular}

Fig. 1. IoT Verticals

Source: Authors' own

\section{IOT'S Influence on HR}

As IoT is getting more indispensable to humans, the importance of the same will be even realized more in the different organizations as far as role of HR is concerned. Allowing an organizational environment which prospers on the Internet of Things will permit HR to put into practice employee welfare like working in timings which are flexible to employees, working in remote locations and continuously managing performance in a whole[8].

Execution of IoT is pertinent to a handful of other sectors in an institution. All of these areas will require HR to successfully integrate IoT into everyday life.

Develop a quantified working environment for synergy creation - IoT has undoubtedly paved the way for different applications in different fields such as healthcare, industrial IoT, etc [9]. Because of these organizations, efforts will have to be made to find out how to help HR connect their employees to ensure better engagement. HR must try to encourage its workers to use wearable devices at work so that data can be collected and HR can further use this data to develop insights of travel trends, employee productivity, impact of a change in location on the productivity of employees, cross cultural communications etc.

Addressing Employee Vitality- Another important job responsibility of a HR manager is to make it possible for workers to improve their wellbeing i.e. physical as well as emotional health. Healthy employees are found to be more productive. Smart watches, fitness bands, fitness apps on mobiles can help employees track their health and also pursue a healthy lifestyle. HR can find more information regarding their workforce vitality using the data generated through these devices. It can contribute to improvements in the ergonomics of the workplace, working hours or nutritious food cafeteria.

Enabling Better Recruitments- Recruitment is one of the most important areas in the human resources feature. IoT can help in aiding efficient recruitment process by keeping an eye on the employees' response during recruitment [10]. This will subsequently affect in bringing down the attrition rate. It can be achieved by 
putting an interview candidate in a virtual environment, and by monitoring them via wearable devices, seeing their response. One can also enable the potential employee to virtually experience their future office spaces before taking the final decision.

IoT enabled by Artificial Intelligence can make the selection process devoid of bias and bring in more employee diversity.

Measuring Employee Behavior and Identification- Office spaces these days are flooded with badge wearing employees. Employees use these badges to gain access in the office premises or to mark their attendance. These badges can be used to track the location of employees, their stress levels through their heart beats or voice tones and pitch etc. Thus, these badges can serve as sociometric badges[11]. In the logistics and supply chain industry these badges can also be used to monitor the drivers speed, to eliminate the idle time between deliveries, to identify safer routes etc.

Enabling an Insightful and Agile Organization- Workforce analytics which till now seemed to be something unreal will soon be a reality. IoT will help organizations gain insights into employee productivity[12]. Not only this, it will also reduce the HR reaction time to employee issue thereby enhancing their agility. The data which was previously invisible will now be eye-catching. Thus, innovation is the key in developing new applications which that help organizations connect to their workforce thereby enhancing their efficiency.

It is very obvious that when organizations are going to deploy new technology, they will face resistance from older employees, issues pertaining to job security among their existing employees or the breach of data privacy. Having the right mix of employees will help the HR tackle these issues effectively. If the workforce is such that they are eager to adapt to new technology, they are flexible and agile, it would be easy to imbibe IoT across the organization.

\section{How IOT Brings Quantified Employee-Delloitte Canada}

World athletes monitor how fast they go, how much weight it bears, How many calories they take, how much sleep they require, and how much oxygen they breathe. Keeping a track of these variables, helps optimize the performance of the athlete and they can gain competitive edge. The use of technology helps them collect information regarding their energy utilization and also conservation, monitoring their daily workouts and also to determine their peak performance time.

Delloitte Canada calls their employees as "corporate athletes" who are involved in too many emails, too many meetings and above all too many decisions. As business people, we must monitor our productivity in the same way as athletes do. The desire to calculate, monitor and regulate ourselves has created a whole industry for companies producing wearable compute procedure, health monitors and mobile message gear at a feverish speed. What are those wearable apps doing for us? We give us details of our sleep, exercise, diet, activity, and pulsation, create the quantify character, driven by the Internet of Things ( IoT) expertise infrastructure.

Although did he or she become the quantified employee when the quantified self comes into the office? Lots of employers will hope so: by looking at efficiency, travel and location trends, communication habits, and how teams collaborate, HR personnel could intend at creating extra friendly and productive job environment with oceans of worker wearables data. Yet there are real obstacles to this program involving a workforce, starting with the reality that workers are not generally comfortable offering unlimited exposure to their employers in their activities and more.

As the quantified workplace demand increases, fuelled by a emphasis on efficiency, fitness, health and the enhancement of the working surroundings, following two important questions arises:

- What interesting ways IoT technology should businesses use Does that push workers to address issues and improve work processes?

- Why can managers conquer opposition, and persuade staff to measure consciously?

Delloite Canada is one such example where they have redesigned their work space on the basis of data collected through the sociometric badges of the employees.

Deloitte Canada identified few employees to wear sociometric badges which were capable of measuring their location, their voice and movement etc. these devices were capable of hearing the voice tones of employees and could deduce when employees were under stress, when they were present in meetings, when they were sitting idle and Certain efficiency steps. Deloitte Canada gave the following insights into the project outcomes:

- Employees are further "happy" in office buildings with more windows and lights than in closed spaces and private rooms.

- Cross functional teams are mare engaging and leads to better results than employees working alone.

- $\quad$ Big meeting rooms have a more beneficial effect than small conference rooms. 
- Workers have a tendency to put effort while being in lesser communities, so working physically next to others uplift their satisfaction by increasing efficiency rates.

Deloitte Canada and others used the above results to update all of the main bureaus and teams.

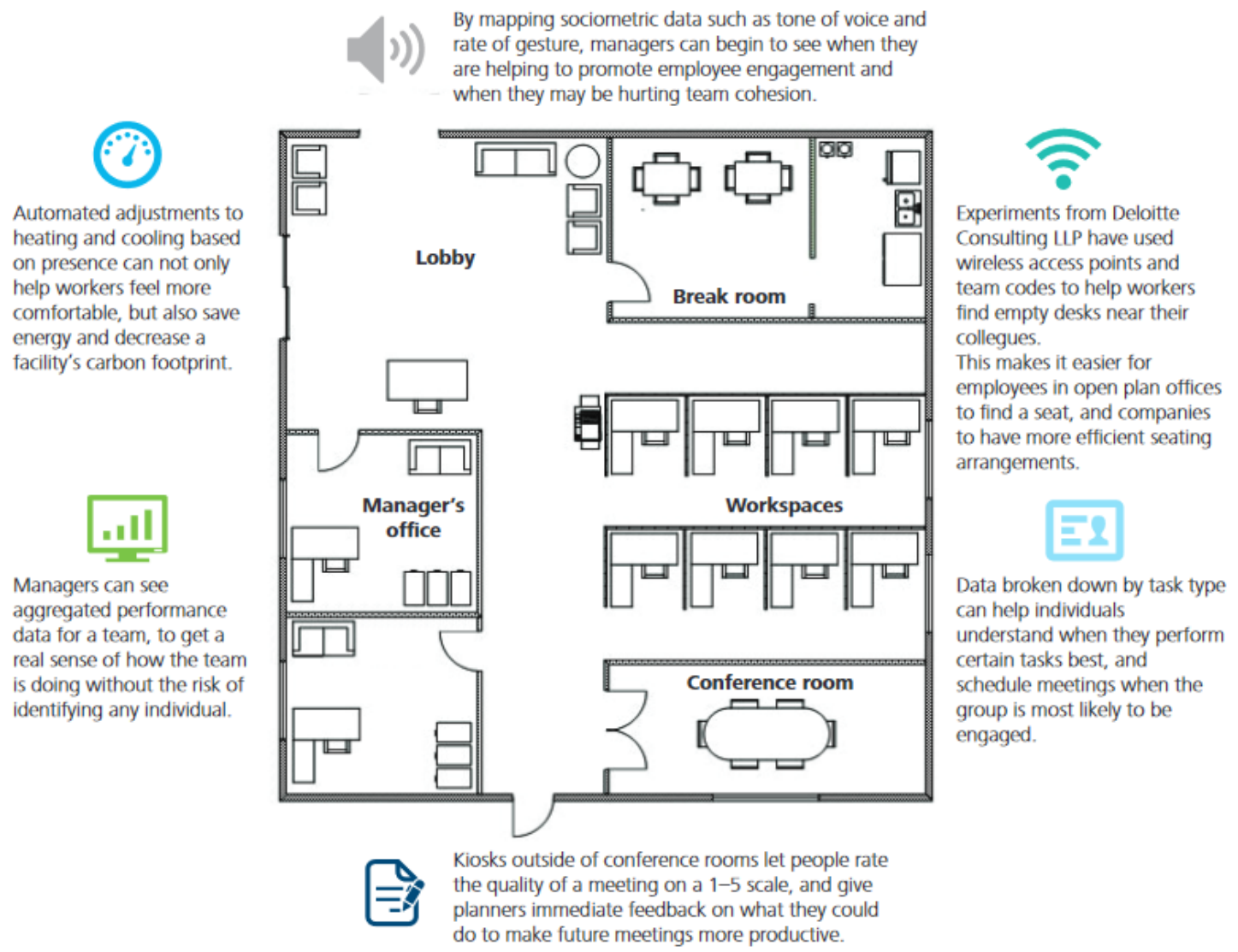

Fig.2. Possible IoT Applications in the Workplace

Source: Delloitte's analysis [15]

Companies are today looking for a variety of paths to integrate IoT technology and human intelligence in the business domain. (See figure 2.)

- A range of package delivery companies are now installing truck sensors to track parameters such as direction, speed, braking, safety of certain drive train components and even seatbelt drivers.. Working with the planning system, analysts can use these data to automatically plan hyper-efficient routes, which eliminate left turns, schedule maintenance when necessary and even the unnecessary idling. An IoTbased network allowed UPS to reduce idling time by 15.4 million minutes in a single year, and distribution routes by over 1.7 million miles, saving over 200,000 gallons of fuel.

- Many healthcare providers and several retailers are now offering fitness trackers and wellness apps to staff that allow employees to share calorie counts, walked step flights and other workout activities with team members, facilitating healthy living and exercise competition. Both strategies may have positive effects on the efficiency and health of workers.

- HR is well aware of how contagious social ills such as regulatory danger, bribery and toxic workplace attitudes can be - that if someone has a poor attitude, those who work closely with or sit next to him can well follow suit. Thus, through tracking and evaluating personal behaviors such as venue, voice tone, email traffic, and other criteria - all of which IoT apps may support - companies may identify and take action to minimize where "conduct risk" lies inside the company. For financial services firms, where subtle cultural shifts on what is appropriate can lead to regulatory crackdowns or illegal trading, these tactics can not only help raise the morale of the workers, but also stave off the challenges to the very survival of the sector.

- MIT computer scientist Sandy Pentland created badges with sensors capturing more than 100 data points on how people communicate, how many face-to - face encounters they have, and how often they chat, listen or interrupt. His team found, for example, that bringing together call center staff for lunch at the 
same time ( usually spaced so people can stay on the phones) greatly improved productivity: employee contact increased 18\%, anxiety and stress (as measured by voice tone) fell 19\%, and most notably, the call completion metric improved $23 \%$. Gradually, industry is trying to apply these principles to the everyday work. Hitachi, for example, has long "instrumented" its employees with smart badges and now offers other businesses a variety of employee "happiness tracking" tools.

\section{Challenges in the Way of IOT}

Every technology comes with certain challenges and IoT is no exception. Some of them are:

Security breaches: IoT enables many devices to connect in ways that one could never imagine before. Thus, IoT is vulnerable to hacking and malfunction too[13]. It has been found that $70 \%$ of the IoT devices are prone to serious risks.

Standards and regulations: IoT devices have been found to operate in disruptive ways due to lack of best practices and standards in designing. This leads to issues relating to configuring, networking and managing a good number of IoT devices.

Privacy: Data security problems have become popular in electronic electronics, such as phone tracking systems, smart TVs, etc. You can integrate voice recognition or visuals with other devices to keep a watch over user activities[14]. Secretly listening to personal conversations and keeping an eye on the movements of the consumer is the greatest threat.

\section{Discussion}

Information drives the IoT in or out of the workplace and the reliability of technology and software depends on the quality, legitimacy and abundance of that information. So little reporting or disinformation — can cause inaccurate and unsupportive study; a lot of information raises the question of hard-to-manage scenario, leaving executives with no knowledge of how to arrange columns of estimates.

IoT sensors will offer a wealth of embarrassment to data analysts with employee buy-in: data as basic as how many daily steps (and where and when) a worker takes to precise sociometric measures of his or her feelings and voice tone in various working circumstances before equipping a whole population with smart watches and related recognition Badges, consider your priorities carefully: what kind of question are you trying to solve? Start with the business problems you want to address first, then decide what data you need.

Now: How do I get the needed data? Most employees become reticent again — understandably so — to quantify themselves, provide their superiors with unrestricted IoT-assisted admittance to their meetings, activities, and interactions. As U.C. Berkeley professor of management Morten Hansen put it, "The quantified self is grotesque." Despite confidentiality assurances, should any company ensure the details never goes, and will never be used during annual inspection once potentially harmful data is in the system? Hansen advises that employers strive for "less results, input less but better, emphasis and change in selective behavior eminence, not amount.

Consider a surveillance analysis of an employee at a large American insurance company, where other employees were tracked when performing their daily duties and others were not. Once it came time for employees to measure their own individual results, $80 \%$ of those in the monitoring group identified production quantity as the most significant factor in self-assessment, while $85 \%$ of unmonitored employees reported quality of customer service and team work. The reliance on metrics has significantly reduced the standard of service.

If only the organization had reported, "We are going to start a project to understand how we can help you improve productivity and service, by analyzing what types of support and activities create the most value," Officials may have reacted in a different way. Nonetheless, based on their daily work experience, they could have collaborated by proposing especially applicable IoT-driven metrics.

Note also that high-quality data collection also involves the processing of knowledge over a longer timeframe. Responsibilities of employees may shift radically during definite period of the month, year or season, not to mention their behavior near the end of a stressful trimester. Everyday job actions and outcomes in the summer would not equal those in the fall, This means you'd like to collect data as long as you can.

While experts know all too well about people analytics or employee engagement, statistical integrity and reliability are key - and a continuing challenge. Assume you are collecting data on employee travel and work behavior and infer what determines sales efficiency or other company predictor. If the sample of data isn't statistically accurate and checked, you can only determine that "high performance salespeople want to travel a lot" — that should or should not be useful details. Correlation isn't causation, as usual.

Another reason to focus on gathering data carefully is to avoid the popular issue of numerous processes within an organization that ends up with inaccurate, incomplete and duplicated details. For example, if you want to track the position of employees or the email information, IT needs to be addressed to make certain that you 
have a single, centralized resource with clear isolation and defense controls, as well as data storage and allotment strategies. Most HR departments have not yet developed data governance policies and procedures which are likely to become more important as the current data trickle becomes a flood. To protect the data, track access and keep people responsible for safety and quality standards, you should have a clear process. Figure 3, Illustrates best practices in constructing quantified workplaces.

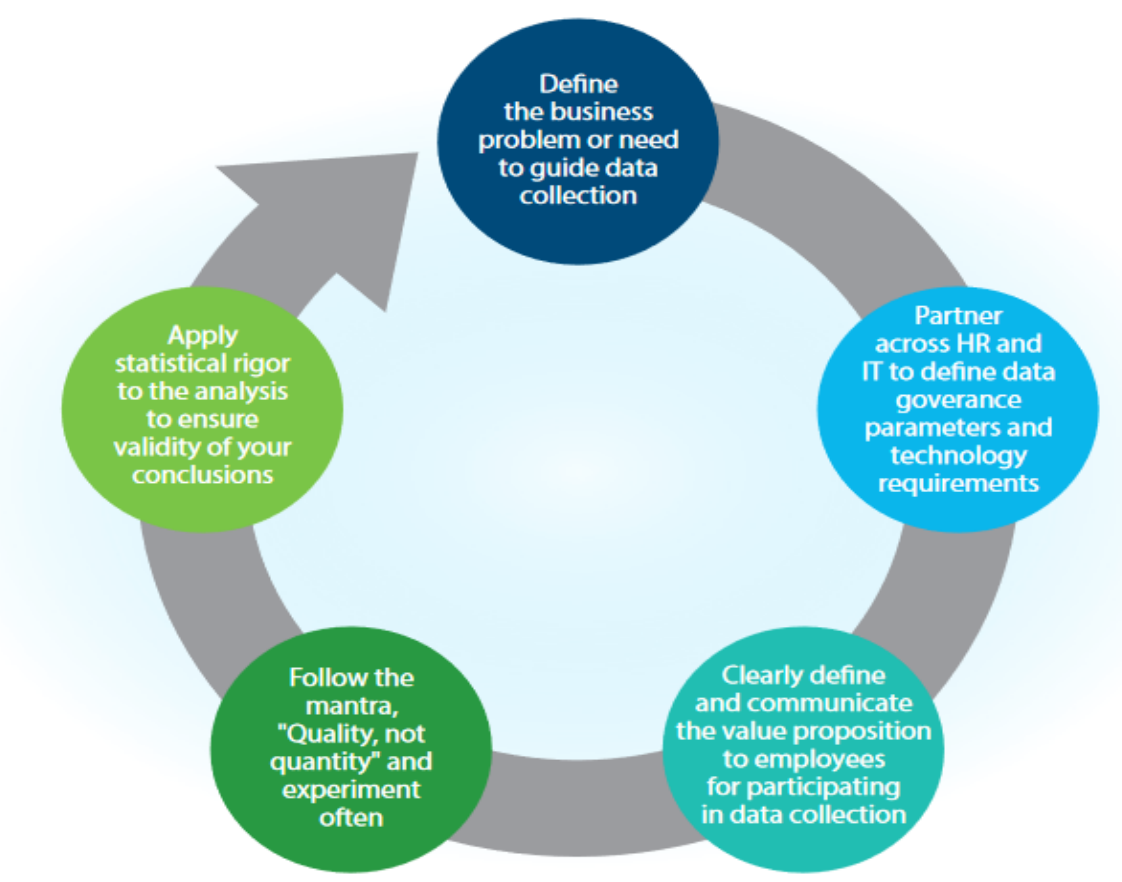

Fig. 3. Designing a Quantified Workforce

Source: Delloitte's analysis[15]

\section{Conclusion}

Organizations are facing a new generation of technology and it will have a huge impact on the way the companies do the job. IoT applications have the power to change necessarily the way organization conduct and measure their work. The HR department is in a unique position for collecting and using data generated by IoT.

Just as athletes can measure their performance through wearables, even employees can use IoT devices to their advantage and make their workplace more efficient. If corporate leaders carefully align business needs with the priorities, privacy issues and preferences of workers, they will solve challenges in the workplace and make the company more successful. With the help of IoT, sky is the limit.

\section{References}

1. Constant, N., Douglas-Prawl, O., Johnson, S., \& Mankodiya, K. (2015). Pulse-Glasses: An unobtrusive, wearable HR monitor with Internet-of-Things functionality. In IEEE 12th International Conference on Wearable and Implantable Body Sensor Networks (BSN), 1-5.

2. Miorandi, D., Sicari, S., De Pellegrini, F., \& Chlamtac, I. (2012). Internet of things: Vision, applications and research challenges. Ad hoc networks, 10(7), 1497-1516.

3. Agrawal, S., \& Das, M.L. (2011). Internet of Things-A paradigm shift of future Internet applications. In Nirma University International Conference on Engineering, 1-7.

4. Strohmeier, S. (2018). Smart HRM-a Delphi study on the application and consequences of the Internet of Things in Human Resource Management. The International Journal of Human Resource Management, 1-30.

5. Pan, Y., White, J., Schmidt, D.C., Elhabashy, A., Sturm, L., Camelio, J., \& Williams, C. (2017). Taxonomies for Reasoning about Cyber-physical Attacks in IoT-based Manufacturing Systems. International Journal of Interactive Multimedia \& Artificial Intelligence, 4(3), 45-54.

6. Sanchez, J.L.C., Bernabe, J.B., \& Skarmeta, A.F. (2018). Integration of anonymous credential systems in IoT constrained environments. IEEE Access, 6, 4767-4778. 
7. Mohsin, M., Anwar, Z., Husari, G., Al-Shaer, E., \& Rahman, M.A. (2016). IoTSAT: A formal framework for security analysis of the internet of things (IoT). In IEEE Conference on Communications and Network Security (CNS), 180-188.

8. Shin, D. (2014). A socio-technical framework for Internet-of-Things design: A human-centered design for the Internet of Things. Telematics and Informatics, 31(4), 519-531.

9. Palattella, M.R., Dohler, M., Grieco, A., Rizzo, G., Torsner, J., Engel, T., \& Ladid, L. (2016). Internet of things in the $5 \mathrm{G}$ era: Enablers, architecture, and business models. IEEE Journal on Selected Areas in Communications, 34(3), 510-527.

10. Nallakaruppan, M.K., \& Kumaran, U.S. (2018). Quick fix for obstacles emerging in management recruitment measure using IOT-based candidate selection. Service Oriented Computing and Applications, 12(3-4), 275-284.

11. Matraszek, M., Rüb, I., Konorski, P., Batorski, D., \& Iwanicki, K. (2020, February). Human Nature: The Subject and the Headache of IoT-Based Sociometric Studies. In EWSN, 265-270.

12. Gaur, B., Shukla, V.K., \& Verma, A. (2019). Strengthening people analytics through wearable IOT device for real-time data collection. In international conference on automation, computational and technology management (ICACTM), 555-560.

13. Rizvi, S., Kurtz, A., Pfeffer, J., \& Rizvi, M. (2018). Securing the Internet of Things (IoT): A security taxonomy for IoT. In 17th IEEE International Conference on Trust, Security and Privacy in Computing and Communications/12th IEEE International Conference on Big Data Science and Engineering (TrustCom/ BigDataSE), 163-168.

14. Xu, X., Fu, S., Qi, L., Zhang, X., Liu, Q., He, Q., \& Li, S. (2018). An IoT-oriented data placement method with privacy preservation in cloud environment. Journal of Network and Computer Applications, 124, 148-157.

15. Bersin, J., Mariani, J., \& Monahan, K. (2016). Will IoT technology bring us the quantified employee? The Internet of Things in human resources. 